\title{
Managing Climate Change Risks in Africa - A Global Perspective
}

\section{Introduction}

Africa is believed to be the continent most vulnerable to climate change impacts (Carabine et al., 2014; Niang et al., 2014; Porter et al., 2014). Water and food systems, public health, and agricultural livelihoods are projected to be severely disrupted by climate change, including enhanced drought, sea level rise, changes in the incidence and prevalence of vector-borne diseases, changes in the ranges and yields of food and non-food crops, and more frequent occurrence of extreme climate driven bio-economic events. These projected changes are expected to exacerbate already high levels of food and water insecurity, poverty, and poor health, and undermine economic development (Dasgupta et al., 2014; Murray and Ebi, 2012; World Bank, 2010). Adaptation will have to be a priority for climate policy on the continent this century, where 'adaptation' refers to efforts across scales to build resilience and reduce vulnerability to the impacts of climate change.

There is now a rapidly developing body of literature on adaptation taking place at household and community levels in Africa (Dube and Sekhwela, 2008) (Dabi et al., 2008; Ensor and Berger, 2009; Osman-Elasha et al., 2008; Wellard et al., 2012). The responses of farmers and communities to climate impacts, supported by the actions of civil society and international development organizations, are illustrative of significant capacity for innovation to climate impacts at local to regional levels in Africa. Yet there are cogent arguments (see Morton et al. 2014) that the scale and rate of climate change will exceed the capacity of African farmers to adapt through their own skills and knowledge alone. These arguments are compounded by demographic changes, with the population of Africa estimated to increase from 1.2 billion to 2.4 
billion in 2050 , and the continent must greatly increase food production (as well as addressing losses at harvest or post-harvest - (FAO, 2014; Hodges et al., 2014) to respond to an era of rapid climate change (FAO, 2014). There is an urgent need for science to support adaptation decision making across scales in view of the difficulty and uncertainty that is associated with agricultural productivity and food security in Africa (Lobell et al., 2008). While the challenge of adaptation for Africa is formidable, the need to adapt is increasingly recognized, from the community level through regional and national government levels to the donor community (Bizikova et al., 2015; De Souza et al., 2015; Lwasa, 2015; Stringer et al., 2014; Stringer et al., 2009). If adaptation is to gain traction, it will need co-ordination, leadership, and recognition of the need to adapt (Moss et al., 2013; Sherman and Ford, 2014).

Adaptation in Africa faces many challenges, spanning technical, political, institutional and organisational, economic, social and biophysical dimensions. As a technical example, developing better projections of climate change impacts is important for adaptation (Katz et al., 2013), but is constrained in many African nations by a lack of historical information on weather and climate (Conway and Schipper, 2011). Adaptation requires institutional leadership for developing policies and programs to respond to future risks, catalyze interest and action of stakeholders, and for distributing resources (Ford and King, 2015; Smith et al., 2009), yet institutional failure in rural extension services and lack of consideration of emerging problems from climate risks have been identified as region-wide barriers (Fankhauser and McDermott, 2014; Ford et al., 2015; Lynam and Twomlow, 2014; Morton et al., 2014). The costs of adaptation are also affected by significant development deficits, with some estimates suggesting the costs of adapting in Africa could exceed US\$50 billion/yr (UNEP, 2015). In fact, a new UNEP report shows five time higher than previous estimate with the cost of adaptation in developing countries including 
countries in Africa estimated to be between $\$ 280$ and $\$ 500$ billion per year by 2050 (UNEP, 2016), suggesting that cost of adaptation in Africa may rise above $\$ 100$ billion per year by 2050 . While adaptation finance through the United Nations Framework Convention on Climate Change (UNFCCC) will help offset some of these costs, it is not of the magnitude required for climate proofing (Donner et al., 2011; Fankhauser and Schmidt-Traub, 2011; UNEP, 2015). All these challenges are coupled with societal transitions, population growth, and rapid urbanization facing African nations.

The challenge of adaptation for low income countries in general and Africa in particular, has been long recognized, and in 2001 the UNFCCC initiated the creation of the National Adaptation Programmes of Action (NAPAs) for the Least Developed Countries (LDC) to identify and establish priorities for adaptation assistance. Of 54 countries in Africa, 33 countries have produced NAPAs at the time of writing (as of May 2016-UNFCCC database). NAPAs remain an important tool in the management of climate change risks in Africa, identifying priority activities and catalyzing country-level interest in climate change, yet the link between NAPAs and key at-risk sectors such as agriculture and water resources remain unclear. As a result, mainstreaming NAPAs into these sectors have faced many challenges partly due to lack of data and limited technical capacity (Stringer, et al., 2009), undermining the implementation of adaptation activities in African nations (Hepworth, 2010; Oates et al., 2011). This demonstrates that despite NAPAs being produced by many Africa countries, defining adaptation priorities at the national level still remains a huge problem. For example, water insecurity which represents one of the major problems in Ethiopia, received little attention in the nation's NAPA document (Oates et al., 2011), reflecting limited consultation with the key stakeholders and weak policy processes (Yirgu et al., 2013). Other studies illustrate that the adoption of new innovation in 
agricultural production is poorly integrated and articulated in NAPA documents for other African countries including Sierra Leone, Gambia, Sudan, Botswana, Benin, Uganda, Mozambique and Chad (UNEP, 2015)(Stringer, et al., 2009)(Morton et al. 2014). Herein, more comprehensive action plans that address the challenges of climate change have been advocated in view of the limited scope of NAPAs (Held et al., 2013). In Ethiopia, for example, an Ethiopian Programme of Adaptation to Climate Change (EPA-CC) was introduced to replace the NAPA because the latter was lacking a strategic vision for the country's sustainable developing agenda (Held et al., 2013). In most of these countries, adaptation initiatives are limited in scale and often fail to express the number of beneficiaries in NAPA documentation, suggesting poor engagement of local institutions and other relevant stakeholders in NAPA projects (Smucker et al., 2015)(UNEP 2015). More broadly, a lack of multi-level stakeholder engagement in decision-making process for adaptation action in Africa has been noted in the literature (Bryan et al., 2009; Koch et al., 2006; Ziervogel and Taylor, 2008), thereby calling for policy responses or new NAPAs to tackle this problem. A new approach is considered urgent in view of the severity of climate vulnerability in many African countries.

Our knowledge of adaptation experiences at farmer and community-level in Africa has grown in recent years. Ford et al (2015), for example, document and characterize the status of adaptation in 'hotspot' nations in Africa based on a systematic review of the peer-reviewed and grey literature, as well as policy documents; Mannke (2011) evaluates community-based adaptation initiatives in Africa; a number of African farmer-level examples of adaptation are collated by Dasgupta et al. (2014), while the IPCC chapter on Africa in AR5 charts current scientific understanding on multiple aspects of climate change on the continent. Our knowledge of the perspectives of stakeholders on adaptation beyond the level of the community in Africa, 
however, is limited, one exception being Kumamoto and Mills (2012) who investigate what 20 African countries who are part of the Africa Adaptation Programme perceive to be priority adaptation interventions based on a review of national level program reports. This dearth of documentation on stakeholder perspectives constrains understanding on the extent to which the continent is ready for adaptation, and limits our understanding of the challenges faced. This study responds to this gap, documenting and examining the views of stakeholders on adaptation in academia, national government and UN agencies, donors, non-governmental organizations, farmers, and extension officers. The study addresses the following questions:

1) What is the current status of adaptation policy in Africa and how effective is this policy?

2) What are the key ingredients required to manage and implement adaptation activities successfully?

3) Is current climate finance sufficient and accessible and how can it be managed better?

Key themes from interviews with various stakeholders are presented as a series of concerns about adaptation (building upon the approach of Ford et al., 2015), with an emphasis on water, agriculture, and cross cutting issues. The work fills a critical gap, helping inform strategic planning on where support and action is needed to mainstream adaptation in both the public and private sector by building a roadmap for action based on insights that emerged from the interviews. While other studies have engaged with some of these questions for specific topics and or countries/regions of Africa, to our knowledge none have done so based on interviews with stakeholders, including high-level stakeholders, continent-wide and across scales, regarding the adaptation activities. 


\section{Methods}

\subsection{Expert interviews}

Expert interviews have been used in diverse contexts in the climate and environmental change literature, including in projects identifying and characterizing vulnerability to climate change, documenting observations of climate change impacts, identifying needs and priorities for adaptation, and evaluating adaptation barriers and opportunities (Hagerman et al., 2010)(Ford et al. 2010)(Granger Morgan et al., 2001; Hagerman et al., 2010; Sovacool et al., 2012). In this study, expert interviews were used to develop insight into how policymakers, researchers, practitioners, and other relevant stakeholders view climate change adaptation problems and seek to provide solutions in view of their roles in decision-making processes. While experts' viewpoints may not necessarily lead to a consensus, the participation and roles of various experts can be used to highlight different kinds of agreement and disagreement over a wide range of issues (Morgan and Keith, 1995). We also sought to document perspectives of farmers on adaptation in selected countries, who have a central role in adaptation in an African context. While other studies have documented strategies by which farming households have been responding to climate change in Africa, along with factors affecting adaptive capacity (MugiNgenga et al., 2016; Perez et al., 2015), little is known about farmers' perspectives on planned adaptation, the adaptation policies and actions of governments and donors as a response to climate change, and what is missing from those policies and actions. 


\subsection{Data collection}

This study documents and characterizes understanding and diverse views of various expert stakeholders on adaptation to the impact of climate change in Africa through qualitative semistructured interviews. The semi-structured questions included an informal checklist as described in the appendix. Semi-structured interviews were conducted among five stakeholders groups as described in Table 1: 1) high-level decision makers in UN- agencies and donors (multilateral) $(\mathrm{n}=11) ; 2)$ high-level decision makers in national governments $(\mathrm{n}=11) ; 3)$ nongovernmental organizations (NGOs) $(n=5) ; 4)$ Think-tank, research institutes and universities ( academia) (n=34); 5) Farmers' and agricultural extension officers to provide local context $(n=276)$. A total of 337 interviews from five stakeholder groups were conducted between 2013 and 2015 by the lead author. These were conducted during the $3^{\text {rd }}$ and $4^{\text {th }}$ annual conference on climate change and development in Africa (Addis Ababa, Ethiopia, 21-23 October 2013; Marrakesh, Morocco 8-10 October 2014), the 'Beyond Rio+20: Emerging Challenges and Opportunities' conference (18-22 November 2013, Accra, Ghana), with extension officers and farmer interviews conducted in Ethiopia, Lesotho and Rwanda in 2013, Uganda in 2014 and in Ghana in 2015).

Thirty interviews were conducted via Skype/telephone and were mostly with researchers or experts who were not present at the conferences, while the rest were conducted face-to-face either through individual interview or focus group discussion. Focus group discussion was mostly used among farmers, involving 4-8 people in a group. Focus groups are an excellent tool for exploring respondents' attitudes and for making clarification and providing a better understanding of the topic (Krueger, 1994). With this type of approach, we were able to gather 
their opinions and gain insight into how they think and respond to the impact of climate change. Most farmer interviews represent an activity of IFAD's Country Specific Strategic Opportunities Programme, including climate change, which was coordinated with the national governments and reflected their agenda on adaptation policy that targets climate change vulnerability among the farmers. Farmers were made aware of their roles in adaptation planning especially for those with extensive local farming experience which can help in tackling climate change impact. While these farmers are not representative of Africa, the majority of those interviewed practice familybased smallholder farming similar to other farmers across many African countries. In addition, some of the experts or policymakers interviewed have important local knowledge about the traditional farming practices. For example, an agricultural policymaker, also a farmer, shared his experience about changing climate.

We used a purposive sampling strategy to select a diversity of respondents in the 5 stakeholder groups, capturing individuals with experience in numerous African nations and those involved in a variety of roles and sectors. For those in governments and UN agencies, we sought to interview those in high-level roles by exploring issues relating to climate policy, finance, adaptation activities and strategies, and trying to understand how adaptation decision-making processes work at the national and international levels. We asked those in academic and research institutions similar questions to those directed at the policymakers and other relevant questions that relate to collection and management of data, research and development, climate prediction and projection uncertainties in Africa and their roles in decision making. Questions relating to awareness, understanding and experience of the impact of climate change were directed to farmers and extension officers, with the regional focus of interviews reflecting locations where the authors are working with communities in climate-related projects. 
Participant selection was purposive and focused on recruiting a wide range of individuals with expert knowledge of or responsibility for adaptation activities in Africa. One of the disadvantages of purposive sampling, is that the range and degree of variation in a purposive sample is difficult to determine at the beginning of the study (Palinkas et al., 2015), but interviewing a wide range of stakeholders has increased the value of the study. Moreover, we tried as much as possible to reduce bias by a) introducing the independent nature of our research, its objectives and its Africa-wide nature, and b) sticking to a pre-defined checklist of adaptationrelated questions as described in the Appendix. But rather to identify a strategy that emphasizes differences and similarities for the purpose of answering the questions posed to them (Palinkas et al., 2015), as described in Table 2. We cannot conclude that we eliminated bias - for example there may have been a residual effect by which African decision-makers perceived us as representatives of donor organizations with immediate interests in allocating funding - but the sampling procedure and interview method certainly reduced it.

While the link between mitigation and adaptation was mentioned among stakeholders during the interviews, authors have decided not to discuss this aspect of climate policy in order not distract our attention from adaption which is being advocated for reducing vulnerability in Africa. Given that adaptation has the highest priority in Africa, it is important to understand some of the confounding factors across different groups of stakeholders which is one key area of focus in this research study.

Prior to telephone or Skype interviews, most international experts were contacted by the lead author via emails which explained the reasons for requesting for the interviews. Out of 50 emails sent to the experts, 30 agreed to be interviewed. This agreement led to arrangement of the 
interview dates between the lead author and the experts. At the conferences, the lead author also conducted the interviews with different stakeholders groups. Individuals were contacted beforehand and times were scheduled after agreeing to be interviewed. In some cases, an interview was granted immediately having explained the reasons why she/he was being asked for the interview. The lead author and one of the co-authors from IFAD conducted farmers' interviews. Farmers were contacted either through the Ministry of Agriculture or local government in target country, and permission was given to interview the farmers after providing detail and clarification as to why they were asked to be interviewed. All the respondents gave informed consent verbally and agreed to be audio-recorded. Respondents' views are anonymized here except where express permission was given to include their names or other identifying characteristics.

[insert Table 1 about here]

\subsection{Data Analysis}

The interviews were audio recorded and notes taken simultaneously. After the audio recordings, interviews were transcribed and analysed using a coding scheme applied in a qualitative data analysis software (Hyper Research 2007). Data were organized into manageable units by focusing on relevant messages and the types of lessons that could be learnt from stakeholders interviews (Bogdan and Biklen, 1982). We carried out a detailed analysis of stakeholder perspectives by following six phases as described by (Braun and Clarke, 2006) to guide our dataset and key themes. First, reading and re-reading of the dataset was done after transcribing the interviews. Initial codes (phase 2) were generated after re-reading using the following ideas that emerged: a) Experience on adaptation climate data, scenarios and impact models; b) How 
adaptation policies are formulated and implemented; and c) How adaptation projects are financed. Phase 3 resulted in grouping into themes and sub-themes after generating the codes followed by the review of these themes (phase 4)- this allowed for checking for overlap and duplication across the thematic classifications. Theme names were refined (phase 5) and overarching themes were identified and validated (phase 6). Outcomes of the data analysis are described in results and discussion which forms the basis of the theme from the interviews

\section{Results}

The results are organized according to overarching themes emerging from interviews with various stakeholder groups on the management of climate change risks in Africa.

\subsection{Climate data, scenarios and impacts models are insufficient for supporting adaptation}

The first major theme to emerge from the interviews concerned the widespread perception that key sectors including water resources and agriculture are being significantly affected by climate

change. Such concern emerged from the climate sensitivity faced by African nations, along with the negative effects of 'unusual climatic conditions' already being observed, which many respondents believed were linked to climate change.

Individual and focus group discussions with both male and female farmers across sub-Saharan Africa (Burkina Faso, Ethiopia, Ghana, Rwanda and Uganda) specifically cited unreliability in the onset and cessation of the rains, uncertainty about the duration of the rainy season, and the long dry spells that fall within the season, as major constraints to crop production, harvest and post-harvest activities. According to an agricultural policymaker in Burkina Faso, "irregular 
rainfall was causing unexpected delays during the planting seasons, resulting in more frequent shortages of food and a loss of income". Climate forecast information is received mainly through the radio, and was described to be frequently inaccurate, not capturing the localised vagaries of weather. In contrast, for the livestock farmers in Lesotho, the early onset of frost coincides with the shearing of Angora goats and endangers the survival of the young that produce the most valuable mohair. These observations mirror the scholarship documenting perceptions of climate change in Africa, yet well-documented historical data as it relates to the experience of farmers is scarce and often anecdotal. Few nations have reliable and detailed long-term datasets from which to determine if or how the climate is changing at regional to local levels. One agronomist noted that "there was insufficient instrumental data to tell you what the change over the past 100 years has been, which is a major problem for Africa, and requires an expanded and a more high resolution monitoring and observation system on the continent."

The biggest challenge for preparing for future impacts as reported across interviews, however, concerned the limited understanding of the distribution of potential future climate change impacts, particularly those related to precipitation. At the level of agricultural decision making for example, the significant difference in precipitation projections by models (Feng et al., 2013) - in terms of the magnitude, timing, and direction of projected change-was reported to limit their usability in planning. Many of these concerns mirror similar debates in the literature, but a number of issues specifically pertaining to African projections were also reported. For example, climate scientists interviewed consistently reported that there is a lack of agreement on the best practices and techniques for downscaling climate projections that are crucial to understanding the uncertainties in regional temperature and precipitation projection across the continent. This is compounded by the poorly understood interaction of land and ocean 
temperatures, and regional and global-scale teleconnections that influence the African climate (Kilroy, 2015), along with limited historical data from which to validate models.

Compounding uncertainties over future projections, interviews documented concerns over the models used to simulate potential sectoral impacts. Agriculture emerged as a major concern here, with economists and policy experts emphasizing the need for climate data that relate directly to the vulnerability of food systems and rural livelihoods, including the magnitude and frequency of extremes, the speed and spatial distribution of change, and the magnitude of change in relation to thresholds of crop production. Furthermore, adapting to climate impacts requires an understanding of the systems being impacted, not only the climate forcing, yet data collection on food production, utilization and distribution was described to be limited at best and non-existent in many cases. Approaches that aim to identify and prioritize locally appropriate climate smart agriculture (CSA) technologies will need to address this context-specific multi-dimensional complexity in agricultural systems. The climate smart agriculture rapid appraisal (CSA-RA) is a mixed method approach that has been developed to address this (Mwongera et al., 2016). Issues surrounding uncertainty in climate projections and impacts modeling have received attention in the general adaptation scholarship (Antón et al., 2013; Dovers, 2009; Fazey et al., 2010; Morton, 2007), and the question as to whether adaptation policy can be formulated in the context of uncertain future projections generated significant debate here. On the one hand, some climate scientists noted that improving climate data collection, particularly at the regional scale, is essential, enabling better downscaled projections necessary for underpinning robust decision making. Equally, others (mostly climate scientists) argued that adaptation decisions can be taken in absence of a full understanding of how the future climate might change, by increasing emphasis on enhancing resilience to current climate risks. Put simply, if we cannot help farmers 
manage todays' climate risks, how can we help them manage future risks? (Cooper et al., 2009). Addressing data gaps and improving the quality of climate projections, however, were widely argued to be essential for informing adaptation in Africa, requiring action by national governments, donors, and UN agencies.

\subsection{The adaptation response to-date has been limited, fragmented, with limited engagement of local actors}

It was widely reported that adaptation has received little attention to-date from many African governments, particularly within agriculture and concerning farmers' preparedness and response strategies to climate variability and change. As a UN respondent noted, governments across the continent are yet to prioritize developing adaptation measures such as transmitting information to farmers about changes in temperature and rainfall that will affect crop choices, while the need to enhance farm and water management practices remain poorly integrated into adaptation strategies that are being developed and proposed-a problem common to many countries in Africa (Conway and Schipper, 2011; Ford et al., 2015). One agronomist explained that a lack of focused biological and socio-economic agricultural research and development (R\&D) will affect the ability of farmers to respond to a variety of potential impacts of climate change. Specifically, it was noted that crops that are most sensitive to climate change (e.g. maize, beans, coffee) have received little attention as part of adaptation actions from both national and international governments. Furthermore, it was reported that where adaptive strategies have been proposed for agriculture, in a majority of African countries these are often fragmented and not fully integrated into existing policy processes, potentially being ineffective or even maladaptive. 
Another component of this fragmentation concerns the lack of adaptation planning that explicitly recognizes or aligns with the country level priorities, with adaptation often developed in isolation from national action plans. As such, adaptation was reported to be often addressed in isolation from other issues, limiting the effectiveness of proposed policies and programing, creating confusion, and missing opportunities for mainstreaming. A number of interviews also reported concern over the dominance of adaptation discourse focusing on the national level with limited sub-national and local engagement, suggesting that national adaptation policy may not translate into local adaptation (Ford et al., 2015). One of the Southern African representatives from the Ministry of Agriculture, for example, argued that limited participation of local experts continues to undermine adaptation projects, with adaptation planning controlled by the national government and multilateral agencies. Equally, the lack of local expertise on adaptation planning and knowledge on climate change was reported to present a major challenge facing greater local engagement across African nations. Too often, the expertise in country is found in the disaster risk reduction units, with limited capacity in the traditional development institutions. In Mozambique, for example, the International Fund for Agricultural Development (IFAD) has specifically targeted capacity building on climate change to support the participation of the commercial section of the Ministry of Agriculture in climate policy formulation and development programming.

\subsection{Adaptation policies and programs are too narrowly focused}

Building upon concern over the fragmented nature of adaptation, climate policy experts also noted that adaptation projects typically overlook fundamental development issues including food insecurity, poverty, health, and population distribution that will determine vulnerability and 
resilience to the impacts of climate change, instead focusing primarily on risks directly linked to climate change. Similar concerns have been expressed in the general scholarship, with increasing recognition that effective, sustainable, and ethical adaptation needs to integrate development considerations alongside climate change impacts (Thurlow et al., 2012)(Sherman et al., 2016).

The policy experts further argued that the principal challenges facing Africa, particularly in rural regions, concern climate variability and not climate change per se, with non-climatic stresses increasing vulnerability to climate-related risks. One policy expert argued that some climate change impacts may not be noticeable yet, particularly at the rural community levels, but lowregret measures and win-win measures will have to deliver against their inability to respond to the impact of climate change. Yet many current adaptation finance mechanisms require adaptation funding to explicitly respond to climate change, rather than broader development issues (Inderberg et al., 2014). Failure to address these broader issues can compromise adaptation: according to the UNDP representative in West Africa, for example, a failure to link adaptation planning to disaster risk reduction would significantly undermine the success of any plans.

Infrastructure was mentioned as one of the key components that can aid the implementation of adaptation projects but yet to be prioritized in agricultural sector. It was argued that setting up supportive infrastructure or maintaining existing infrastructure can be problematic in many African countries, which in turn slows down adaptation projects. One adaptation expert argued that lack of investment in infrastructure such as water resource storage systems could be a hindrance to adaptation in water sector. Another respondent also argued that rain water harvesting technology and supplementary irrigation system can be important in dealing with 
climate variability but limited access to credit has constrained farmers' ability to employ such technologies. An agricultural economist surmised that a lack of a good transportation system could be a major problem in adapting to climate change in urban areas particularly during the extreme weather events when there is greater demand for food from farmers outside of the city. Because of the poor connectivity between cities and agricultural producing areas, part of the city economy that require adaptation may suffer in the future. Similarly, another economist noted: "so another example of a non-crop activity that you would do to help with climate change for agriculture is to build better roads. Build more roads, and make them resilient to different climate stresses. To do that, farmers get higher prices for their outputs, lower prices for their inputs that they use, so they make more money and they are more resilient. So this income effect which is needed for individuals to deal with these coming challenges would be helped by better roads."

\subsection{Adaptation finance is insufficient, but capacity to develop and implement adaptation measures is also a limiting factor}

Current levels of international funding for adaptation are not sufficient, with approximately USD \$1-2bn a year flowing to Africa specifically for adaptation, compared to a projected need of about USD5bn/year by 2020 (UNEP, 2015). However, results from our study highlight that even if the necessary funds were to materialize, the capacity to implement adaptation projects on the scale required would remain a constraining factor.

Participants widely acknowledged that given the lack of resources and other pressing needs facing African nations, that effective adaptation practices are directly linked to finance. The 
UNFCCC representative emphasized that the preparation of NAPAs by individual African countries is fundamental herein, providing the basis for accessing funds from the Global Environment Facilities (GEF) to manage adaptation projects and at the time of this interview \$20 million had been allocated to each country from the GEF. The same representative mentioned that only a few countries in Africa have used their \$20 million while the majority is yet to use the fund despite having prepared NAPAs. Similarly, a high-level representative from the GEF mentioned that different types of funds are available, including GEF Trust Funds, GEF's Least Developed Countries Fund (LDCF) and Special Climate Change Fund (SCCF), but also the Adaptation Fund (AF), and most recently the Green Climate Fund (GCF), to support adaptation projects in Africa. But these are different types of funds that are subject to different disbursement procedures, even though they are all under the UNFCCC umbrella, with the GEF acting as Secretariat for all of the above except the GCF. Despite the existence of a number of funding platforms, interviews representing African governments and some UN-agencies raised fundamental questions as to how funds related to adaptation are accessed and the types of projects that are funded in Africa.

UN representatives consistently reported challenges at the national level as constraining the ability of nations to access adaptation funds, reflecting weak institutional support and limited by capacity at the local and national levels to administer funds. For example, it was reported that there are very few trained personnel across relevant ministries to assist countries in developing planning that incorporates climate change. On the other hand, respondents including a member of the African Negotiator Group argued that cumbersome procedures and bureaucratic bottlenecks in accessing the funds from different sources including UNFCCC and GEF dissuade many African countries from producing clear plans for adaptation projects. These respondents 
explained that procedures for applying to adaptation funds can be both unclear, and different between sectors or categories of adaptation, and therefore make funding difficult to access by African governments. For example, procedures for accessing funds designated for adaptation to flooding under LDCF can be different from procedures for adaptation in agricultural water management under the same fund.

The issue of fund accessibility was contentious in the interviews. UN representatives, for example, including a manager of the funds, reported that the rules and procedures are clearly stated. The GEF representative argued that LDCF and SCCF have relatively light procedures, although also stated that the GEF trust fund is distributed based on a series of parameters and a rather complicated formula that result into different allocations for different countries. When this happens, a country with lower capacity tends to take a lot of time to prepare the right project to access the funds. Here, he agreed that the system is flawed due to this challenge but also mentioned that in a way the system is fairer to those countries that really need the funds and that are prepared to access the funds. Additionally, an interviewee from the United Nations Development Programme (UNDP) noted that the main challenge was the preparation of a sound project with a logical framework that is well-structured to allow easy monitoring and evaluation, so that the project can be implemented without delays. To ensure that earmarked climate and environmental finance are channeled to smallholders, IFAD launched the 'Adaptation for Smallholder Agriculture Programme' (ASAP) in September 2012 to enhance IFAD supported programmes, and has mobilized US\$366 million as of September 2015. ASAP is currently the largest adaptation programme for smallholder farmers globally and works within the broader IFAD mandate to enable poor rural people to improve their food security and nutrition, raise their incomes and strengthen their resilience. To date 23 ASAP investments in low and lower- 
middle income countries of Africa have been designed and approved by the IFAD Executive Board, ranging from US\$ 2-15 million per project. ASAP projects aim to climate-proof existing IFAD rural development projects, which appears to be a rational way of mainstreaming adaptation within the context of broader development goals (as discussed in section 3.3), and overcoming the capacity constraints of building stand-alone adaptation projects ex-novo.

\section{Discussion}

This paper draws upon interviews with stakeholders involved in adaptation decision making in Africa to identify and examine the challenges facing efforts to reduce vulnerability and enhance resilience to climate change. The work is particularly timely given the climate risks facing the continent and the recent Paris Agreement which specifies a greater role for adaptation in climate policy, especially in low income regions. The work expands on previous studies which have mostly focused on documenting perspectives and needs for adaptation at a community level or focused on a limited number of African nations, or based analysis on a review of the literature, to provide continent-wide insights from a diversity of stakeholders. In the discussion we tease out key themes surrounding the challenges identified (Table 2)

[insert Table 2 about here]

\subsection{Moving forward: A roadmap for action on adaptation in Africa}

The stakeholder reflections on adaptation as profiled above, collectively identify a number of insights for developing effective adaptation policy in Africa.

First, investment is needed to improve climate data, scenarios and impacts models. This requires new approaches and partnerships across key UN agencies (including UNFCCC, UNDP, World 
Meteorological Organization (WMO), United Nations Environment Programme (UNEP) and Food and Agriculture Organization (FAO), International Fund for Agricultural Development (IFAD) the African Centre for Meteorological Applications for Development (ACMAD), and national governments to identify the main problems across various sectors and develop partnerships with relevant stakeholders'. African governments need to overhaul meteorological departments by revisiting their mission statements with respect to agriculture and climate change, upgrading equipment and increasing the number of trained personnel capable of undertaking the analyses of long term data sets and delivering relevant knowledge management products. Climate data needs to be strengthened through resourcing various meteorological agencies in African countries to collect, manage, store, analyse climate data and share information in a format various sectors of the economy require on a long term basis. Strengthening the observation network is crucial for forecasting, projecting and developing understanding into Africa's unique climate and its vulnerability to the impact of climate change (Conway and Mustelin, 2014; Niang et al., 2014; UNDP, 2011). This needs to also engage local communities and decision makers to incorporate their knowledge on climatic conditions, observed changes, and determinants of vulnerability. Recent studies emphasize the need to consider climate issues, collect data and develop models at the value-chain and food system levels whilst considering the role of farm households (Stathers et al., 2013; Thornton and Herrero, 2015). An African research network program that connects local communities, farmers, researchers and meteorological departments should be encouraged for data collection; similar models have been proposed for other data poor regions (Huntington, 2011).

Second, governments need to increase agricultural $R \& D$. Past experience suggests there is limited funding for agricultural $R \& D$ in Africa and current efforts are being led by both bilateral 
and multilateral donors (Lynam et al., 2016). Although, according to Lynam et al., (2016), when compared to multilateral donors, a larger role is being played by bilateral donors. Example of leading bilateral donors include the Gates and Rockefeller foundations and these organization continue to fill gaps created by the public sector (Herdt, 2012). Advanced developing countries such as China and Brazil continues to speed up investment in agriculture R\&D (Pardey et al., 2016), particularly to adapt to climate change among other top priorities. According to Pardey et al., (2016), in China, more than $\$ 6$ billion (mostly from private sector and about $57 \%$ of domestic spending), was spent on agricultural R\&D in 2011. Given the African' vulnerability to climate change, agricultural R\&D should, for example, focus on crops and varieties that are resilient to different temperature and precipitation regimes, as well as farming practices. R\&D can play a significant role herein in enhancing the adaptive capacity of farming systems (Adenle et al., 2015). Most respondents agreed that key ministries such as planning, agriculture, land and water resources must invest in $\mathrm{R} \& \mathrm{D}$ for adaptation, especially in drought tolerant crops, early warning systems, water efficiency, farm power, mechanization, green energy and post-harvest technologies. More importantly, R\&D should be targeted towards understanding the interaction between food systems and climate change. An important research task for the future is therefore to develop an integrated assessment framework and action plan suitable for adaptation to climate change in Africa, and to mainstream climate resilience into various sectors and development strategies both at the local and national levels.

\subsection{Strengthening and supporting the implementation of adaptation activities}

The engagement of various stakeholders and institutions simultaneously at the different levels of government such as local, national, and regional is critical to climate change policy formulation 
(Clark et al., 2002; Cooper and Wheeler, 2015; Huntjens et al., 2012). The current climate regime in Africa, however, has not engaged many of the actors whose participation and role is crucial to decision-making, particularly in adaptation policy formulation. The lack of engagement of relevant stakeholders often undermines adaptation planning and decision-making particularly at the national level (Stringer, et al., 2014)(Brown, 2011), thereby leading to limited ownership of adaptation projects. This is reflected in some of the challenges identified by different stakeholder groups (e.g. Table 2). Closely linked to concern over the narrow focus of adaptation projects, interviews often reported a lack of clarity among governments on what 'adaptation' is, with concern that such confusion will compromise the development and implementation of adaptation projects; the scholarship more generally has also raised concerns that 'adaptation' is a vague, confusing, and malleable concept (Dupuis and Biesbroek, 2013; Stringer et al., 2014; Suckall et al., 2015)(Sherman et al,, 2016).

Based on the interviews, we propose the 4-Cs framework in view of weak existing adaptation policy framework: climate projection, climate education, climate governance, and climate finance (Figure 1).

4.2.1 Climate projection-This could be placed under meteorological departments and their mandates modified to reflect the responsibility of coordinating data management and development of climate information products with the Ministries of Agriculture, research institutions and farm communities. Better quantification of uncertainties will require a stronger partnership among these stakeholders by bringing together their resources and expertise in solving the problem related to climate projection. In fact their expertise can be leveraged with those from regional centres and advanced 
countries. This is in line with a climate scientist interviewed who noted that, "a purpose based strategic focus for integration and coordination efforts will have a much greater impact in improving the models, making them more refined and more complex to be more realistic". Furthermore, efforts should be geared toward collection and use of demographic data especially mapped to the geography of current and future climate-related challenges in most vulnerable regions (Lutz and Muttaraq, 2017). This can help in addressing challenges related to economy, location, size and characteristics of the need to achieve adaptation objectives. Understanding population dynamics can play a significant role in development and implementation of adaptation programmes because it has been linked to social and economic development as well as secure livelihoods (Cohen, 2010). Therefore, this approach can be a powerful tool in implementing adaptation projects and building adaptive capacity in Africa.

\subsubsection{Climate education- Ministries of Education in partnership with Ministries of} Agriculture, other sectoral ministries and NGOs can play an important role in climate education and raising awareness among the public, specifically targeting youth and women's groups. Ministries of Education should support teaching climate change within the national educational system with emphasis on its current impact and potential role of youth in tackling future impacts and increasing challenges posed by climate change. In rural areas, programmes need to be implemented to promote and disseminate innovation from multiple sources (farmers themselves, research institutes, input suppliers), and integrate the concerns of farmers (including women and youth) into higher-level decision-making. Building engagement and 
communication capacity of community leaders will help increase awareness levels and foster better understanding of adaptation among local people. Local communication specialists with greater engagement skill will complement the efforts of community leaders and NGOs in coordinating and disseminating adaptation information effectively to the public.

4.2.3 Climate governance- While external actors such as donors and NGOs often take the lead role in adaptation implementation, climate governance should involve key stakeholders with more responsibility and leadership at different levels of government (including local/provincial government) within the country. More importantly, it should be led by ministries and departments responsible for overall development planning in each country and coordinated with the Ministries of Agriculture and Water Resources and other key ministries including finance. Climate change issues are critically interlinked across these ministries. Understanding these linkages requires better partnership and collaboration among the ministries while coordinating with the donors and NGOs in implementing adaptation actions. Each ministry has an important role to play especially aligning its objectives with other ministries in order to provide an effective solution to the problem of climate change. Moreover, national government as led by the ministries should engage local government by understanding their concerns and providing appropriate solutions.

4.2.4 Climate finance-Adaptation activities related to finance needs to be well coordinated and must be led by the Ministry of Finance, coordinating adaptation funds and attracting funds from private sector and donors. The Ministry of Finance should serve 
as a focal point for all climate change related matters between the national governments, bilateral and international donors. This ministry should be able to support and provide guidance where necessary to the other relevant ministries to facilitate better negotiation for the individual country. Their support should be extended to data assessment and monitoring of climate finance for transparency and accountability.

The 4-Cs framework could be instrumental and effective in coordinating adaptation planning and has the potential to address fundamental challenges associated with the development and implementation of adaptation projects in Africa. The development of an adaptation policy framework must take a "whole-of-government approach" that engages all the relevant ministries and other key stakeholders, and should be emphasized by the UNFCCC and other implementing agencies. While this study has focused on adaptation need and policies, there is nothing in this framework that would be incompatible with the planning, governance and implementation of appropriate mitigation policies.

[insert Figure 1 about here]

Figure 1: An integrated framework based on the 4-Cs approach]

\subsection{Encouraging a well-coordinated capacity building programme}

Effective capacity building programmes and access to climate finance will determine the effectiveness and legitimacy of implementing adaptation projects in Africa. The current service delivery model, especially the one targeting capacity building and disbursement of funds 
coordinated by the implementing agencies, does not seem to work for the reasons described above. Moreover, some of these implementing agencies can be overstretched due to increasing demand of technical support. To address part of these problems, the establishment of regional capacity building hubs should be encouraged. Such African focused hubs should aim to strengthen the training, monitoring and evaluation of programs, and to increase capacities in the implementation of various adaptation projects aligned with the interests of local and national governments. This would also help remove backlogs in processing and accessing funds and help provide the capacity and technical expertise required to implement projects. This effort could be led by the New Partnership for Africa's Development (NEPAD) in partnership with the UNEP, FAO and UNDP, and promoted as a complementary effort to strengthen existing national and regional programs of NEPAD in addressing the threats of climate change in Africa.

The development and sustainability of any beneficial programs toward tacking climate change in developing countries, including those in Africa, will require significant investment especially in infrastructure development to strengthen adaptation activities. A recent World Bank report emphasizes the integration of climate change in the planning and design of infrastructure investment in Africa (Cervigni et al., 2015). While developed countries have pledged financial support to vulnerable regions including Africa, particularly to meet the cost of adaptation (UNFCCC, 1996), too little progress has been achieved. Given the potential impacts of climate change in Africa, mobilizing $\$ 100$ billion a year by 2020 under the agreement for the Green Climate Fund may not be enough. In light of the Paris climate agreement, there is hope that this agreement may encourage developed countries to further comment more financial resources into the Green Climate Fund. But the question remains how Africa will have a fair share of this fund 
such that it recognizes and helps address the true scale of overall climate change challenge in the continent.

\section{Conclusion}

This paper examines perspectives of diverse stakeholders on the challenge of adapting to climate change in Africa. Key challenges emerging across stakeholder groups are related to insufficient climate data, lack of well-coordinated adaptation activities, limited access to finance, and fragmented adaptation programmes. We argue that current adaptation policy and implementation of adaptation projects by bilateral and multilateral donors is unlikely to deliver good results in many African countries. Responding to this challenge, the 4-Cs framework- climate projection, climate education, climate governance and climate finance-was proposed to address part of these problems. With this framework, better project coordination and capacity building programmes, better access to finance and management of funds, and engagement of relevant stakeholders can foster effective implementation of adaptation projects. We believe that the 4-Cs framework as spelt out in this article could effectively contribute to decision-making processes at various levels of governments and to a more successful implementation of adaptation activities in Africa. While we understand certain impediments to the proposed framework particularly given the politics, bureaucracy and complexity of multi-stakeholder processes at the negotiation table, national and regional government have an important role to play especially in ensuring that a cordial relationship is established to implement this framework. 


\section{References}

Adenle, A.A., Azadi, H., Arbiol, J., 2015. Global assessment of technological innovation for climate change adaptation and mitigation in developing world. Journal of Environmental Management 161, 261275.

1

Antón, J., Cattaneo, A., Kimura, S., Lankoski, J., 2013. Agricultural risk management policies under climate uncertainty. Global Environmental Change 23, 1726-1736.

Bizikova, L., Parry, J.-E., Karami, J., Echeverria, D., 2015. Review of key initiatives and approaches to adaptation planning at the national level in semi-arid areas. Regional Environmental Change 15, 837850.

Bogdan, R.C., Biklen, S.K., 1982. Qualitative research for education: An introduction to theory and methods. Boston, MA: Allyn \& Bacon.

Braun, V., Clarke, V., 2006. Using thematic analysis in psychology. Qualitative Research in Psychology, 3, pp. 77-101.

Brown, D., 2011. Making the linkages between climate change adaptation and spatial planning in Malawi. Environmental Science \& Policy 14, 940-949.

Bryan, E., Deressa, T.T., Gbetibouo, G.A., Ringler, C., 2009. Adaptation to climate change in Ethiopia and South Africa: options and constraints. Environmental Science \& Policy 12, 413-426.

Burke, M., Lobell, D., 2010. Food Security and Adaptation to Climate Change: What Do We Know?, in: Lobell, D., Burke, M. (Eds.), Climate Change and Food Security: Adapting Agriculture to a Warmer World. Springer Netherlands, Dordrecht, pp. 133-153.

Carabine, E., Lemma, A., Dupar, M., Jones, L., Mulugetta, Y., 2014. What's in it for Africa? The Intergovernmental Panel on Climate Change (IPCC). The Fifth Assessment Report.

Cervigni, R., Liden, R., Neumann, J.E., Strzepek, K.M., 2015. Enhancing the Climate Resilience of Africa's Infrastructure.The Power and Water Sectors. World Bank, Washington, DC.

Clark, W., Mitchell, R., Cash, D., Alcock, F., 2002. Information as influence: how institutions mediate the impacts of scientific assessments on global environmental affairs. John F. Kennedy School of Government, Harvard University, Faculty Research Working Papers Series, RWP02-044.

Cohen, J.E., 2010. Population and climate change. Proc Am Philos Soc;154(2):158-82.

Conway, D., Mustelin, J., 2014. Strategies for improving adaptation practice in developing countries. Nature Clim. Change 4, 339-342.

Conway, D., Schipper, E.L.F., 2011. Adaptation to climate change in Africa: Challenges and opportunities identified from Ethiopia. Global Environmental Change 21, 227-237.

Cooper, P., Rao, K.P.C., Singh, P., Dimes, J., Traore, P.S., Rao, K., Dixit, P., Twomlow, S., 2009. Farming with current and future climate risk: Advancing a 'Hypothesis of Hope' for rain-fed agriculture in the Semi-Arid Tropics. Journal of SAT Agricultural Research 7, 1-19.

Cooper, S.J., Wheeler, T., 2015. Adaptive governance: Livelihood innovation for climate resilience in Uganda. Geoforum 65, 96-107.

Dabi, D.D., Nyong, A.O., Adepetu, A.A., Ihemegbulem, V.I., 2008. Past, present and future adaptation by rural households of northern Nigeria. In Leary, N., Adejuwon, J., Barros, V., Burton, I., Kulkarni, J. and Lasco, R. (eds.) Climate change and adaptation, Earthscan, London and Sterling VA, pp. 147-162. Dasgupta, P., Morton, J.F., Dodman, D., Karapinar, B., Meza, F., Rivera-Ferre, M.G., Toure Sarr, A., Vincent, K.E., 2014. Rural areas. In: Climate Change 2014: Impacts, Adaptation, and Vulnerability. Part A: Global and Sectoral Aspects. Contribution of Working Group II to the Fifth Assessment Report of the Intergovernmental Panel on Climate Change [Field, C.B., V.R. Barros, D.J. Dokken, K.J. Mach, M.D. Mastrandrea, T.E. Bilir, M. Chatterjee, K.L. Ebi, Y.O. Estrada, R.C. Genova, B. Girma, E.S. Kissel, A.N. Levy, 
S. MacCracken, P.R. Mastrandrea, and L.L. White (eds.)]. Cambridge University Press, Cambridge, United Kingdom and New York, NY, USA, pp. 613-657.

De Souza, K., Kituyi, E., Harvey, B., Leone, M., Murali, K.S., Ford, J.D., 2015. Vulnerability to climate change in three hot spots in Africa and Asia: key issues for policy-relevant adaptation and resiliencebuilding research. Regional Environmental Change 15, 747-753.

Donner, S.D., Kandlikar, M., Zerriffi, H., 2011. Preparing to manage climate change financing. Science 334, 908-909.

Dovers, S., 2009. Normalizing adaptation. Global Environmental Change 19, 4-6.

Dube, O.P., Sekhwela, B.M., 2008. Indigenous knowledge, institutions and practices for coping with variable climate in the Limpopo Basin of Botswana. In Leary, N., Adejuwon, J., Barros, V., Burton, I., Kulkarni, J. and Lasco, R. (eds.) Climate change and adaptation, Earthscan, London and Sterling VA, pp. 71-99.

Dupuis, J., Biesbroek, R., 2013. Comparing apples and oranges: The dependent variable problem in comparing and evaluating climate change adaptation policies. Global Environmental Change-Human and Policy Dimensions 23, 1476-1487.

Ensor, J., Berger, R., 2009. Understanding climate change adaptation: Lessons from community-based approaches. Practical Action Publishing.

Fankhauser, S., McDermott, T.K.J., 2014. Understanding the adaptation deficit: Why are poor countries more vulnerable to climate events than rich countries? Global Environmental Change-Human and Policy Dimensions 27, 9-18.

Fankhauser, S., Schmidt-Traub, G., 2011. From adaptation to climate-resilient development: The costs of climate-proofing the Millennium Development Goals in Africa. Climate and Development 3, 94-113.

FAO, I.a.W., 2014. The State of Food Insecurity in the World 2014: Strengthening the Enabling Environment for Food Security and Nutrition. Rome, FAO.

http://www.fao.org/3/a-i4030e.pd.

Fazey, I., Gamarra, J.G.P., Fischer, J., Reed, M.S., Stringer, L.C., Christie, M., 2010. Adaptation strategies for reducing vulnerability to future environmental change. Frontiers in Ecology and the Environment 8 , 414-422.

Feng, X., Porporato, A., Rodriguez-Iturbe, I., 2013. Changes in rainfall seasonality in the tropics. Nature Clim. Change 3, 811-815.

Ford, J., Berrang-Ford, L., Bunce, A., McKay, C., Irwin, M., Pearce, T., 2015. The status of climate change adaptation in Africa and Asia. Regional Environmental Change,15:801-814.

Ford, J.D., King, D., 2015. A framework for examining adaptation readiness. Mitigation and Adaptation Strategies for Global Change 20, 505-526.

Granger Morgan, M., Pitelka, L.F., Shevliakova, E., 2001. Elicitation of Expert Judgments of Climate Change Impacts on Forest Ecosystems. Climatic Change 49, 279-307.

Hagerman, S., Dowlatabadi, H., Satterfield, T., McDaniels, T., 2010. Expert views on biodiversity conservation in an era of climate change. Global Environmental Change 20, 192-207.

Held, D., Roger, C., Nag, E.M., 2013. Climate Governance in the Developing World. Wiley, Hoboken, New Jersey.

Hepworth, N.D., 2010. Climate change vulnerability and adaptation preparedness in Tanzania. Heinrich Böll Foundation, Nairobi, Kenya.

https://www.boell.de/sites/default/files/assets/boell.de/images/download de/worldwide/Tanzania Cli mate Change Adaptation Preparedness.pdf. Accessed May 1, 2015. 
Herdt, R.W., 2012. People, institutions, and technology: A personal view of the role of foundations in international agricultural research and development 1960-2010. Food Policy 37, 179-190

Hodges, R., Bernard, M., Rembold, F., 2014. APHLIS -Postharvest cereal losses in Sub-Saharan Africa, their estimation, assessment and reduction. European Commission.

http://publications.jrc.ec.europa.eu/repository/bitstream/JRC92152/lbna26897enn.pdf. Accessed June 2.

Huntington, H.P., 2011. Arctic science: The local perspective. Nature 478, 182-183.

Huntjens, P., Lebel, L., Pahl-Wostl, C., Camkin, J., Schulze, R., Kranz, N., 2012. Institutional design

propositions for the governance of adaptation to climate change in the water sector. Global Environmental Change 22, 67-81.

Inderberg, T.H., Eriksen, S., O'Brien, K., Sygna, L., 2014. (Eds.) Climate Change Adaptation and

Development: Transforming Paradigms and Practices. Routledge

Katz, R.W., Craigmile, P.F., Guttorp, P., Haran, M., Sanso, B., Stein, M.L., 2013. Uncertainty analysis in climate change assessments. Nature Clim. Change 3, 769-771.

Kilroy, G., 2015. A review of the biophysical impacts of climate change in three hotspot regions in Africa and Asia. Regional Environmental Change 15, 771-782.

Koch, I.C., Vogel, C., Patel, Z., 2006. Institutional dynamics and climate change adaptation in South Africa. Mitigation and Adaptation Strategies for Global Change 12, 1323-1339.

Krueger, R.A., 1994. Focus groups: A practical guide for applied research. Second edition. London: Sage Publication.

Lobell, D.B., Burke, M.B., Tebaldi, C., Mastrandrea, M.D., Falcon, W.P., Naylor, R.L., 2008. Prioritizing

Climate Change Adaptation Needs for Food Security in 2030. Science 319, 607-610.

Lwasa, S., 2015. A systematic review of research on climate change adaptation policy and practice in Africa and South Asia deltas. Regional Environmental Change 15, 815-824.

Lutz, W., Muttarak R., 2017. Forecasting societies' adaptive capacities through a demographic metabolism model. Nature Climate Change 7, 177-184.

Lynam, J., Beintema, N., Roseboom, J., Badiane, O. 2016. Agricultural research in Africa: investing in future harvests. International Food Policy Research Institute (IFPRI), Washington D.C. USA.

Lynam, J., Twomlow, S., 2014. A 21st-century Balancing Act: Smallholder farm heterogeneity and costeffective research - Chapter 11 NEW DIRECTIONS FOR SMALLHOLDER AGRICULTURE. Oxford University Press, Oxford

Morgan, G., Keith, D., 1995. Subjective judgments by climate experts. Environmental Science and Technology, 29, pp. 468A-476A.

Morton, J., Kisauzi, D., Ohiomoba, I., Demby, D., Mangheni, M., Moumouni, I., Parkinson, V., Suale, D., Lamboll, R., Nelson, V., Quan, J., 2014. Climate, Agriculture and Knowledge in Africa: Agricultural Research and Advisory Services in the Face of Climate Change. African Forum for Agricultural Advisory Services, Forum for Agricultural Research in Africa, and Natural Resources Institute, University of Greenwich. Chatham, UK.

Morton, J.F., 2007. The impact of climate change on smallholder and subsistence agriculture.

Proceedings of the National Academy of Sciences 104, 19680-19685.

Moss, R.H., Meehl, G.A., Lemos, M.C., Smith, J.B., Arnold, J.R., Arnott, J.C., Behar, D., Brasseur, G.P., Broomell, S.B., Busalacchi, A.J., Dessai, S., Ebi, K.L., Edmonds, J.A., Furlow, J., Goddard, L., Hartmann, 
H.C., Hurrell, J.W., Katzenberger, J.W., Liverman, D.M., Mote, P.W., Moser, S.C., Kumar, A., Pulwarty, R.S., Seyller, E.A., Turner, B.L., II, Washington, W.M., Wilbanks, T.J., 2013. Hell and High Water: PracticeRelevant Adaptation Science. Science 342, 696-698.

Mugi-Ngenga, E.W., Mucheru-Muna, M.W., Mugwe, J.N., Ngetich, F.K., Mairura, F.S., Mugendi, D.N., 2016. Household's socio-economic factors influencing the level of adaptation to climate variability in the dry zones of Eastern Kenya. Journal of Rural Studies 43, 49-60.

Murray, V., Ebi, K.L., 2012. IPCC Special Report on Managing the Risks of Extreme Events and Disasters to Advance Climate Change Adaptation (SREX). Journal of Epidemiology and Community Health 66, 759760.

Mwongera, C., Shikuku, K.M., Twyman, J., Läderach, P., Ampaire, E., Van Asten, P., Twomlow, S., Winowiecki, L.A., 2016. Climate smart agriculture rapid appraisal (CSA-RA): A tool for prioritizing context-specific climate smart agriculture technologies. Agricultural Systems.

Niang, I., Ruppel, O.C., Abdrabo, M.A., Essel, A., Lennard, C., Padgham, J., Urquhart, P., 2014. Africa. In: Climate Change 2014: Impacts, Adaptation, and Vulnerability. Part B: Regional Aspects. Contribution of Working Group II to the Fifth Assessment Report of the Intergovernmental Panel on Climate Change [Barros, V.R., C.B. Field, D.J. Dokken, M.D. Mastrandrea, K.J. Mach, T.E. Bilir, M. Chatterjee, K.L. Ebi, Y.O. Estrada, R.C. Genova, B. Girma, E.S. Kissel, A.N. Levy, S. MacCracken, P.R. Mastrandrea, and L.L. White (eds.)]. Cambridge University Press, Cambridge, United Kingdom and New York, NY, USA, pp. 1199-1265. Oates, N., Conway, D., Calow, R., 2011. The 'mainstreaming' approach to climate change adaptation. Overseas Development Institute Background Note. London: ODI.

Osman-Elasha, B., Goutbi, N., Spanger-Siegfried, E., Dougherty, B., Hanafi, A., Zakieldeen, S., Sanjak, E.A., Atti, H.A., Elhassan, H., 2008. Community development and coping with drought in rural Sudan. In Leary, N., Adejuwon, J., Barros, V., Burton, I., Kulkarni, J. and Lasco, R. (eds.) Climate Change and Adaptation, Earthscan, London and Sterling VA, pp. 90-108.

Palinkas, L.A., Horwitz, S.M., Green, C.A., Wisdom, J.P., Duan, N., Hoagwood, K., 2015. Purposeful sampling for qualitative data collection and analysis in mixed method implementation research. Administration and policy in mental health 42, 533-544.

Pardey, P.G., Chan-Kang, C., Dehmer, S.P., Beddow, J.M., 2016. Agricultural R\&D is on the move. Nature, 537(7620), 301-303.

Perez, C., Jones, E.M., Kristjanson, P., Cramer, L., Thornton, P.K., Förch, W., Barahona, C., 2015. How resilient are farming households and communities to a changing climate in Africa? A gender-based perspective. Global Environmental Change 34, 95-107.

Porter, J.R., Xie, L., Challinor, A.J., Cochrane, K., Howden, S.M., Iqbal, M.M., Lobell, D.B.a.T., M.I. , 2014. Food security and food production systems. In: Climate Change 2014: Impacts, Adaptation, and Vulnerability.Part A: Global and Sectoral Aspects. Contribution of Working Group II to the Fifth Assessment Report of the Intergovernmental Panel on Climate Change. Cambridge University Press, UK pp. 485-533.

Sherman, M.H., Ford, J., 2014. Stakeholder engagement in adaptation interventions: an evaluation of projects in developing nations. Climate Policy, 4(3)417-441.

Smith, J.B., Vogel, J.M., Cromwell, J.E., 2009. An architecture for government action on adaptation to climate change. An editorial comment. Climatic Change 95, 53-61.

Smucker, T.A., Wisner, B., Mascarenhas, A., Munishi, P., Wangui, E.E., Sinha, G., Weiner, D., Bwenge, C., Lovell, E., 2015. Differentiated livelihoods, local institutions, and the adaptation imperative: Assessing climate change adaptation policy in Tanzania. Geoforum 59, 39-50.

Sovacool, B.K., D'Agostino, A.L., Meenawat, H., Rawlani, A., 2012. Expert views of climate change adaptation in least developed Asia. Journal of Environmental Management 97, 78-88. 
Stathers, T., Richard, L., M., B.M., 2013. "Postharvest agriculture in changing climates: its importance to African smallholder farmers." Food Security 5.3: 361-392.

Stringer, L.C., Dougill, A.J., Dyer, J.C., Vincent, K., Fritzsche, F., Leventon, J., Falcao, M.P., Manyakaidze, P., Syampungani, S., Powell, P., Kalaba, G., 2014. Advancing climate compatible development: lessons from southern Africa. Regional Environmental Change 14, 713-725.

Stringer, L.C., Dyer, J.C., Reed, M.S., Dougill, A.J., Twyman, C., Mkwambisi, D., 2009. Adaptations to climate change, drought and desertification: local insights to enhance policy in southern Africa.

Environmental Science \& Policy 12, 748-765.

Suckall, N., Stringer, L.C., Tompkins, E.L., 2015. Presenting Triple-Wins? Assessing Projects That Deliver Adaptation, Mitigation and Development Co-benefits in Rural Sub-Saharan Africa. Ambio 44, 34-41.

Thornton, P.K., Herrero, M., 2015. Adapting to climate change in the mixed crop and livestock farming systems in sub-Saharan Africa. Nature Clim. Change 5, 830-836.

Thurlow, J., Zhu, T., Diao, X., 2012. Current climate variability and future climate change: estimated growth and poverty impacts for Zambia. Review of Development Economics, 16(3), 394-411.

UNDP, 2011. Africa Adaptation Programme: Capacity Building Experiences. Improving Access, Understanding and Application of Climate Data and Information. Discussion Paper Series Vol. 2. June 2. UNEP, 2015. Africa Adaptation Gap 2. Technical Report. http://apps.unep.org/publications/pmtdocuments/-Africa\%E2\%80\%99s Adaptation Gap 2 .pdf.

Accessed August 10.

UNEP, 2016. The Adaptation Finance Gap Report 2016. United Nations Environment Programme (UNEP), Nairobi.

http://drustage.unep.org/adaptationgapreport/sites/unep.org.adaptationgapreport/files/documents/ag r2016.pdf. Accessed 20 May, 2016.

UNFCCC, 1996. Article 4.4. of the United Nations Framework Convention on Climate Change. Report of the Conference of the Parties on its Second Session, Held at Geneva 8-19, July

Wellard, K., Kambewa, D., Snapp, S., 2012. Farmers on the frontline: adaptation and change in Malawi. In Castro, A. P., Taylor, D., \& Brokensha, D. W. (eds.) Climate change and threatened communities: vulnerability, capacity and action, Practical Action Publishing, Rugby, pp.41-56.

World Bank, 2010. World Development Report - Development and climate change, World Development Report, Washington, D.C.

Yirgu, L., Nicol, A., Srinivasan, S., 2013. Warming to Change Climate Policy and Agricultural Development in Ethiopia. FAC, Working Paper 071.

Ziervogel, G., Taylor, A., 2008. Feeling Stressed: Integrating Climate Adaptation with Other Priorities in South Africa, Environment: Science and Policy for Sustainable Development, 50:2, 32-41. 